Purchasing Power Parity, Wages and Inflation in Emerging Markets

Ashima Goyal

Indira Gandhi Institute of Development Research, Mumbai November 2012

http://www.igidr.ac.in/pdf/publication/WP-2012-025.pdf 


\title{
Purchasing Power Parity, Wages and Inflation in Emerging Markets
}

\author{
Ashima Goyal \\ Indira Gandhi Institute of Development Research (IGIDR) \\ General Arun Kumar Vaidya Marg \\ Goregaon (E), Mumbai- 400065, INDIA \\ Email (corresponding author): _ ashima@igidr.ac.in
}

\begin{abstract}
Persistent deviation of real exchange rates from purchasing power parity $(P P P)$ values is a puzzle, since nominal shocks, which cause such deviation, are expected to have only short-run effects. If some goods are non-traded, Balassa Samuelson (BS) showed how such deviations occur and explain why the price level is relatively higher in advanced economies. But then, consistently higher inflation in emerging or developing economies (EDE) is another puzzle. The paper presents a framework giving a new simple proof of the BS result. If the assumption that the price level is fixed for the EDE is dropped, nominal depreciation interacting with different types of wage rigidities can explain higher inflation, as nominal wages rise in response to a nominal depreciation. Then monetary shocks have persistent effects but these shocks can arise from large capital flows independent of changes in domestic money supply. Evidence from India supports the hypotheses.
\end{abstract}

Keywords: Purchasing power parity, inflation differentials, wage rigidities

JEL Code: F41, E31

Acknowledgements:

I thank Shruti Tripathi for research assistance, and Reshma Aguiar for secretarial assistance 


\section{Purchasing Power Parity, Wages and Inflation in Emerging Markets}

\section{Introduction}

Trade arbitrage should cause prices of the same goods to converge across countries when measured in the same currency. This is known as PPP. It implies a real exchange rate of unity. But deviations of the real exchange rate from unity are common and are persistent. Monetary and financial factors explain short-term volatility of nominal exchange rates. But since monetary factors are not expected to have long-term effects, the half-life of three to five years for deviations from PPP is a puzzle. Rogoff (1996) comes to the conclusion that the answer must lie in factors like transactions costs and other barriers that prevent perfect trade integration. But this is an ad hoc explanation. Moreover, while the degree of integration varies with time and the regime in place, the persistence in deviation from PPP has been a constant feature.

A less stringent version of PPP is relative PPP (RPPP). This allows a persistent deviation in price levels across countries, but requires nominal depreciation to equal the inflation differential so that the real exchange rate does not change. But even this is not empirically supported since there are persistent changes in the real exchange rate. Therefore it is worthwhile to explore if monetary shocks can affect the real exchange rate in the longer run.

One failure of PPP is the higher price level of an advanced economy (AE) compared to an emerging or developing economy (EDE) measured in the same currency. A well-known explanation for this puzzle, from Balassa (1964) and Samuelson (1964) (BS), is that although absolute productivity of AEs is higher in the production of all goods, the productivity gap is greater in traded goods. If wages are equalized across all sectors in each country, the price of non-traded goods such as services would be higher in AEs, pushing up the price level. Bhagwati (1984) explains the same facts by postulating higher capital intensity in AEs because of imperfect capital mobility. So in the absence of factor price equalization, wages are higher in AEs. This combined with relatively higher labour intensity in non-traded goods pushes up their relative prices. But there is a second puzzle- although price levels are higher in AEs, inflation tends to be much higher in EDEs, over long periods, so it is not just a feature of wages rising to $\mathrm{AE}$ levels. 
We argue that large nominal shocks and structural features that make for their persistence can explain both puzzles, in the BS framework that distinguishes between traded and non-traded goods. In the PPP theories, real factors - trade arbitragedetermine the real exchange rate. But starting from the seventies, capital flows to EDEs became large and volatile. These shocks drove changes in the nominal exchange rate, as many EDEs moved towards more flexible exchange rate regimes. When these interacted with aspects of structure, such as wage setting behavior, there were persistent effects, including on real exchange rates and on inflation. The second puzzle is explained.

We prove the standard BS result in a simple framework with equal rates of wage growth in both traded and non-traded sectors and then extend it by dropping the assumption that the price level is fixed in the EDE. Our extension allows for shocks such as nominal depreciation and rise in nominal wages, and explains the higher EDE inflation. We also show how a real wage target in terms of food prices can sustain inflation as nominal wages rise in response to a nominal depreciation. This differs from the standard result where changes in the relative money supply growth cause nominal depreciation. Under a floating exchange rate regime, capital flows can change the nominal exchange rate without any change in money supply, so that the nominal depreciation from an outflow is better analyzed as an exogenous shock. Then large capital flows that drive nominal exchange rates and interact with different types of wage rigidities can explain bouts of inflation in EDEs. This reverses the standard explanation that excess money supply causes both inflation and nominal depreciation.

Evidence from India supports the hypotheses. Following the international food price shocks in 2007, India had high food price and wage inflation. Exchange rate volatility was also high as a consequence of risk-on risk-off capital flows following the global financial crisis. We exploit State level wage data to test our hypotheses that nominal depreciation affects inflation through its impact on wages. The results show depreciation and food price inflation significantly and positively affect wages, thus supporting the role of external shocks and wage behavior as explanations of inflation, and validating the extended BS results derived. Although government employment insurance schemes were widely blamed for wage inflation, in regressions only food 
inflation and exchange rate depreciation turn out to be significant. Aggregate demand variables also were not significant.

Policy implications are drawn out. For example, strategic use of exchange rate policy can abort a wage-price cycle in response to an external shock. Since monetary shocks have persistent real effects in the presence of real wage rigidities, macroeconomic policies have a critical role.

The remainder of the paper is as follows: After labour market equilibrium conditions presented in section 2, section 3 derives the basic PPP and BS hypotheses. Section 4 explores wage-price-exchange rate dynamics, section 5 tests the hypotheses with Indian data, section 6 draws out implications for policy, before Section 7 concludes.

\section{The Model}

Consider an emerging or developing economy (EDE) with two sectors producing traded (A) and non-traded (N) goods. Production comprises largely agriculture and services $^{1}$; production of other traded goods is negligible. Services are non-traded articles and agricultural produce is traded. If profit maximization equates nominal wages to the marginal product of labour (MPL) in each sector, then:

$$
\begin{aligned}
& \mathrm{W}_{\mathrm{A}}=\mathrm{P}_{\mathrm{A}} \mathrm{MPL}_{\mathrm{A}}=\mathrm{P}_{\mathrm{A}} \mathrm{a}_{\mathrm{A}} \\
& \mathrm{W}_{\mathrm{N}}=\mathrm{P}_{\mathrm{N}} \mathrm{MPL}_{\mathrm{N}}=\mathrm{P}_{\mathrm{N}} \mathrm{a}_{\mathrm{N}}
\end{aligned}
$$

Nominal wages are $\mathrm{W}$, prices are $\mathrm{P}$, and a is the MPL, assuming a technology with constant returns. Subscripts A and N stand for the agricultural (traded) and non-traded sectors respectively ${ }^{2}$. These equations can be derived from Cobb-Douglas production functions under the assumptions that capital stocks are low enough to be neglected, or that the rental rate equals the world interest rate under perfect capital mobility. The assumption of equal factor intensities in the two sectors is made, without loss of generality, so the relative factor intensity term drops out (see Froot and Rogoff, 1995). Taking logarithms and differentiating, gives the two equations in rates of growth:

\footnotetext{
${ }^{1}$ While this is a simplification in order to isolate the role of agriculture, the low share of manufacturing

2 The convention followed is nominal variables are in capital letters, real or log variables are small letters and rates of growth are denoted by a superscript dot.
} 


$$
\begin{aligned}
& \dot{w}_{A}=\pi_{A}+\dot{a}_{A} \\
& \dot{w}_{N}=\pi_{N}+\dot{a}_{N}
\end{aligned}
$$

Where $\dot{a}_{N}$ is the growth rate of marginal productivity, and $\pi$ represents inflation, with subscripts standing for each sector. With perfect labour mobility between the two sectors, nominal wages and their rates of growth must be the same, so that:

$$
\dot{w}_{A}=\dot{w}_{N}=\dot{w}
$$

At low per capita incomes, food is a major part of the consumption basket. Wages must allow purchase of this basic consumption basket. Productivity falls if wages are below this point. Therefore, assume an efficient or target level $\bar{w}$, of the real product wage in terms of agricultural goods:

$$
\bar{w}=\mathrm{W} / \mathrm{P}_{\mathrm{A}}
$$

It follows log nominal wages, $w$, would be raised in line with log traded goods prices, $\mathrm{p}_{\mathrm{A}}$, to maintain the real wage threshold in the medium-term. If, however, the marginal productivity equation (3) also holds, then the real wage target must be growing at $\dot{a}_{A}$, or:

$$
\dot{\bar{w}}=\dot{a}_{A}
$$

So if $\pi_{\mathrm{A}}>0$, nominal wages must grow at:

$$
\dot{w}=\pi_{A}+\dot{a}_{A}
$$

Equating Equations 3 and 4, when rates of wage growth are the same across the sectors, we have:

$$
\pi_{N}-\pi_{A}=\dot{a}_{A}-\dot{a}_{N}
$$

Workers in one sector are able to extract a wage rise that exceeds own productivity but equals the wage rise in the other sector. Mobility equates wages but is not sufficient to equate productivity, so differentials in the latter persist. Since the population share in $\mathrm{A}$ is large, migration to $\mathrm{N}$ tends to occur only if it pays at least as much as A. Equation (3) holds but equation (4) does not since migrants from A to the $\mathrm{N}$ sector keep wages in $\mathrm{N}$ below the marginal productivity of labour in $\mathrm{N}$. The inflation differential in the two sectors is then given by the productivity differential ${ }^{3}$.

\footnotetext{
${ }^{3}$ If factor intensities differ, so that $\theta_{\mathrm{N}}>\theta_{\mathrm{A}}$, where $\theta$ is the labour share, the equation would become $\pi_{\mathrm{N}}-\pi_{\mathrm{A}}=\left(\theta_{N} / \theta_{\mathrm{A}}\right) \dot{a}_{A}-\dot{a}_{N}$. The relative price of traded goods would rise, or the real exchange rate
} 
While PPP holds in the A sector, prices in the $\mathrm{N}$ sector are set as a mark upon wages. If $\pi_{\mathrm{A}}>0, \pi_{\mathrm{N}}$ would rise with nominal wages.

$$
\pi_{N}=\dot{w}_{N}-\dot{a}_{N}=\pi_{A}+\dot{a}_{A}-\dot{a}_{N}
$$

If $\dot{a}_{N}<\dot{a}_{A}$, the wage rise would be more than the productivity growth in non-traded goods, leading to aggregate inflation that exceeds $\pi_{\mathrm{A}}$. A number of results follow from the basic framework of this section.

\section{Derivations}

Result 1.1 If $\dot{\bar{w}}=\dot{a}_{A}$ so $\dot{w}=\pi_{A}+\dot{a}_{A}$ and $\dot{a}_{N}>\dot{a}_{A}$ then $\pi_{N}<\pi_{A}$, if $\dot{a}_{N}<\dot{a}_{A}$ then $\pi_{N}>\pi_{A}$ Result 1.2 If $\dot{\bar{w}}=\dot{a}_{N}$ so $\dot{w}=\pi_{A}+\dot{a}_{N}$ then $\pi_{\mathrm{N}}=\pi_{\mathrm{A}}$

Result 1.3 If $\dot{\bar{w}}=0$ so $\dot{w}=\pi_{A}$ then $\pi_{N}<\pi_{A}$

Proof: Result 1.1 follows by inspection of equation 6. Result 1.2 since equation 7 becomes $\pi_{N}=\pi_{A}+\dot{a}_{N}-\dot{a}_{N}$, if $\dot{w}=\pi_{A}+\dot{a}_{N}$. Result 1.3 follows since $\pi_{N}=\pi_{A}-\dot{a}_{N}$ is less than $\pi_{\mathrm{A}}$.

Discussion: If $\pi_{\mathrm{A}}$ is rising, $\pi_{\mathrm{N}}$ would rise more, raising aggregate inflation if $\dot{a}_{N}<\dot{a}_{A}$, from equation 7 , which although derived from the logic of price-setting of non-traded goods, is just equation 6 rewritten. If nominal wages grow at the productivity growth rate of the nontradable goods sector, so that $\dot{w}=\pi_{A}+\dot{a}_{N}$, then $\pi_{\mathrm{N}}=\pi_{\mathrm{A}}$. Even this will imply continual inflation if $\pi_{\mathrm{A}}>0$. But the most common case, in an EDE with a large population share in the A sector would be $\dot{a}_{N}>\dot{a}_{A}$ so either Result 1.1 or 1.3 hold with $\pi_{N}<\pi_{A}$.

Since $\pi_{\mathrm{N}}$ increases with $\dot{w}$ and the latter increases with $\pi_{\mathrm{A}}$, all other prices respond to $\pi_{\mathrm{A}}$. Therefore it determines the rate of inflation, in the economy, which will exceed $\pi_{\mathrm{A}}$ if $\dot{a}_{N}<\dot{a}_{A}$ unless the wage target is constant or grows at $\dot{a}_{N}$ not at $\dot{a}_{A}$. 
Unequal sectoral inflation affects the real exchange rate, $\mathrm{Q}$, which is defined as the ratio of the prices of traded to non-traded goods. $\mathrm{Q}=\mathrm{P}_{\mathrm{A}} / \mathrm{P}_{\mathrm{N}}$, so $\mathrm{Q}=\mathrm{SP}^{*}{ }_{\mathrm{A}} / \mathrm{P}_{\mathrm{N}}$ where $\mathrm{S}$ is the nominal or spot exchange rate giving the EDE currency in terms of the $\mathrm{AE}$ currency, and PPP holds in traded goods, that is, $\mathrm{P}_{\mathrm{A}}=\mathrm{SP}^{*}{ }_{\mathrm{A}}^{4}$. PPP does not hold in the economy as a whole or $\mathrm{Q} \neq 1$ if $\mathrm{P}_{\mathrm{A}} \neq \mathrm{P}_{\mathrm{N}}$. But RPPP also does not hold and $\mathrm{Q}$ changes or $\dot{q}>0$ if $\pi_{\mathrm{A}} \neq \pi_{\mathrm{N}}$. Also note that since it affects $\mathrm{P}_{\mathrm{A}}$, the nominal exchange rate $\mathrm{S}$ is a nominal standard, affecting other prices.

Proposition 1: The real exchange rate, $Q$, will be more depreciated in EDEs compared to AEs, providing an explanation for the PPP puzzle.

Proof: If agriculture is stuck at low productivity in an EDE, and the majority of the population is still in agriculture, $\dot{a}_{N}>\dot{a}_{A}$ and wage growth cannot exceed $\pi_{A}+\dot{a}_{A}$. From Result 1 , this implies $\pi_{A}>\pi_{N}$. If $\mathrm{P}_{\mathrm{A}}>\mathrm{P}_{\mathrm{N}}$ then $\mathrm{Q}=\mathrm{P}_{\mathrm{A}} / \mathrm{P}_{\mathrm{N}}$ exceeds the absolute PPP value of unity. Or at least $\dot{q}>0$ so the real exchange rate is depreciating. In AEs the productivity of traded goods is higher, that is, $\dot{a}_{N}^{*}<\dot{a}_{A}^{*}$ and the reverse trends hold. So $\mathrm{Q}$ is more depreciated in EDEs compared to AEs.

This is a non-standard proof based on differing relative productivity growth in the two sectors for the two countries. The standard BS proof for the failure of PPP is based on the relative productivity gaps across the two countries, in the two sectors. It can be given, in terms of our model variables, as follows:

If PPP holds in traded goods, it must be that $\pi_{A}=\dot{s}+\pi_{A}^{*}$. Normalizing $\mathrm{P}_{\mathrm{A}}=\mathrm{S} \mathrm{P}{ }^{*} \mathrm{~A}=$ 1 implies $\pi_{\mathrm{A}}=0$. From equation (6) it follows $\pi_{N}=\dot{a}_{A}-\dot{a}_{N}$, and $\pi_{N}^{*}=\dot{a}_{A}^{*}-\dot{a}_{N}^{*}$. If nontraded good are a share of $(1-\gamma)$ of the total goods, the relative price level or the real bilateral exchange rate for the two countries $\pi^{*}{ }_{N}-\pi_{N}$, can be calculated as:

$$
\pi_{N}^{*}-\pi_{N}=(1-\gamma)\left[\left(\dot{a}_{A}^{*}-\dot{a}_{N}^{*}\right)-\left(\dot{a}_{A}-\dot{a}_{N}\right)=(1-\gamma)\left[\left(\dot{a}_{A}^{*}-\dot{a}_{A}\right)-\left(\dot{a}_{N}^{*}-\dot{a}_{N}\right)\right]\right.
$$

\footnotetext{
intensities is a valid first approximation

${ }^{4}$ The real exchange rate is the relative price comparing the world purchasing power with the purchasing power of domestic currency. If PPP holds in traded goods, then $\mathrm{Q}$ is determined by the difference between $\mathrm{P}_{\mathrm{A}}$ and $\mathrm{P}_{\mathrm{N}}$. The $\log$ arithm of $\mathrm{Q}$ is q. Similarly $\mathrm{s}=\log \mathrm{S}$. $\mathrm{S}$ is written as EDE currency per unit of the foreign country currency.
} 
Although productivity growth is higher in the AE in both goods, the advantage is more in traded goods. It follows non-traded goods inflation will be higher in the $\mathrm{AE}$ and its real exchange rate more appreciated. This is the BS result.

The basic BS assumption is the productivity gap between AEs and EDEs is relatively higher in traded goods. That is:

$$
\dot{a}_{A}^{*}-\dot{a}_{A}>\dot{a}_{N}^{*}-\dot{a}_{N}
$$

This can be written as:

$$
\dot{a}_{A}-\dot{a}_{N}<\dot{a}_{A}^{*}-\dot{a}_{N}^{*}
$$

Equation 10 is satisfied if $\dot{a}_{A}<\dot{a}_{N}$ and $\dot{a}_{A}^{*}>\dot{a}_{N}^{*}$. These inequalities were used to prove Proposition 1.

If we bring in nominal factors by relaxing the normalization assumption that fixes agricultural price levels, we can explain why, even with the BS result, inflation will still be higher in the EDE:

Proposition 2: Inflation will be higher in an EDE, yet its real exchange rate, $Q$, will depreciate relative to an $A E$.

Proof: Aggregate inflation will be a weighted average of inflation in traded and nontraded goods. Since $P_{A}^{*}$ continues to be normalized to unity, $\pi_{A}^{*}=0$. But $\pi_{\mathrm{A}}$ can differ from zero, so $\pi_{N}=\pi_{A}+\dot{a}_{A}-\dot{a}_{N}$. The inflation differential between the AE and the EDE is:

$$
\begin{aligned}
& \pi^{*}-\pi=\gamma\left(\pi_{A}^{*}-\pi_{A}\right)+(1-\gamma)\left(\pi_{N}^{*}-\pi_{N}\right) \\
& \pi^{*}-\pi=\gamma\left(\pi_{A}^{*}-\dot{s}-\pi_{A}^{*}\right)+(1-\gamma)\left[\left(\dot{a}_{A}^{*}-\dot{a}_{N}^{*}\right)-\left(\dot{a}_{A}+\pi_{A}-\dot{a}_{N}\right)\right] \\
& \pi^{*}-\pi=-\gamma \dot{s}+(1-\gamma)\left[\left(\dot{a}_{A}^{*}-\dot{a}_{A}\right)-\left(\dot{a}_{N}^{*}-\dot{a}_{N}\right)-\dot{s}-\pi_{A}^{*}\right]
\end{aligned}
$$




$$
\begin{aligned}
& \pi^{*}-\pi=-\dot{s}+(1-\gamma)\left[\left(\dot{a}_{A}^{*}-\dot{a}_{A}\right)-\left(\dot{a}_{N}^{*}-\dot{a}_{N}\right)\right] \\
& \pi^{*}-\pi=-\dot{s}+\pi_{N}^{*}-\pi_{N}
\end{aligned}
$$

If the EDE currency is depreciating, so $\mathrm{S}$ is rising, or $\dot{s}>0$, the negative term can exceed the positive productivity terms so that EDE inflation exceeds that of the AE.

Note: EDE inflation will continue to be above that in the AE even if $\pi_{A}^{*}>0$ or traded good inflation is positive in the AE, because of the impact of imported traded good inflation on non-traded goods inflation in EDEs.

For $\pi>\pi^{*}$ it must be $\dot{s}>\pi_{N}^{*}-\pi_{N}$. For the BS result to hold $\pi_{N}^{*}>\pi_{N}$. So if $\pi_{A}>\pi_{N}^{*}>\pi_{N}>\pi_{A}^{*}$, or $\dot{s}=\pi_{A}>\pi_{N}^{*}$, inflation is higher in the EDE, yet the BS result is satisfied so $\mathrm{Q}$ is depreciated relative to the AE. Since $\pi_{\mathrm{A}}>\pi_{\mathrm{N}}$, Q rises, since $\pi_{N}^{*}>\pi_{A}^{*}, \mathrm{Q}^{*}$ falls ${ }^{5}$.

BS result requires $\pi_{\mathrm{A}}>\pi_{\mathrm{N}}$ so it follows from Result 1 that either $\dot{\bar{w}}=0$ or $\dot{\bar{w}}=\dot{a}_{A}$ and $\dot{a}_{A}<\dot{a}_{N}$ for the BS result to hold. The first $(\dot{\bar{w}}=0)$ is the case of a pure wage target and $\dot{\bar{w}}=\dot{a}_{A}$ follows from the large share of the EDE population in the agriculture.

If, as in the standard monetary approach, nominal depreciation is driven by a rise in money supply, $\dot{m}=\dot{s}=\dot{p}$ and there is no change in q. But if there are rigidities in price and wage setting $\pi_{A} \neq \pi_{N}, \dot{q} \neq 0$. Although the price-wage mechanism that causes this divergence to persist is a supply side real rigidity, it can be a means of propagating nominal shocks into the longer term, thus contributing a solution to the more general PPP puzzle, of the persistent effects of monetary shocks. These mechanisms show how monetary shocks, which are responsible for the high shortterm volatility of exchange rates, can persist into the longer-run. Under a floating

\footnotetext{
${ }^{5}$ Allowing for industrial production does not materially affect the proof even if the rate of growth of industrial productivity is highest, as long as productivity growth in agriculture, $\dot{a}_{A}$, is below than nontraded services, or $\dot{a}_{A}<\dot{a}_{N}$.
} 
exchange rate, these monetary shocks can just be capital flows that change the nominal exchange rate independently of changes in the money supply ${ }^{6}$.

The BS result has been supported in tests involving very rich and poor countries, in countries like Japan, where agricultural prices play a key role, and for disaggregated OECD data when terms of trade, which pick up prices of consumer goods, are included (Rogoff, 1996). Our analysis suggests that including wages and agricultural productivity may improve explanatory power.

Proposition 2 gave a key role to nominal depreciation and wage adjustment. Nominal shocks such as foreign capital outflows, drive nominal depreciation, and interacting with wage rigidities have persistent effects. We next see how a real wage target can imply a real exchange target. When nominal depreciation causes the real exchange rate to differ from this, sustained inflation can result.

\section{Dynamics of the real and nominal exchange rate, wages and prices}

External balance $(E B)$ or equilibrium in the balance of payments is required in addition to goods market equilibrium or internal balance $(I B)$ in an open economy ${ }^{7}$. Adjustment to full internal and external balance normally requires a combination of a change in price (switching) and in demand (absorption). Expenditure- switching policy is so called since it shifts demand between domestic output and imports. The demand variable can be either the policy variable, government expenditure, or it can be domestic absorption (A, defined as the sum of domestic consumption, C, government expenditure, G, and investment, I) as a whole (Figure 1). The switching variable can either be the nominal exchange rate, in the short period where nominal prices do not completely adjust (Figure 1), or it can be the real exchange rate.

The schedule IB gives internal balance at full employment output, $\mathrm{Y}_{\mathrm{f}}$. The schedule is downward sloping because depreciation and a rise in output both raise demand. So as one rises the other must fall to keep output at a given full employment level. Values

\footnotetext{
${ }^{6}$ Even under a managed float the impact on money supply can vary depending on the degree of reserve accumulation and sterilization.

${ }^{7}$ This section further develops material in Goyal (2010).
} 
above the schedule generate inflation, as a more depreciated exchange rate and higher absorption raise demand. Those below the schedule generate unemployment.

Schedule EB gives external balance or the combinations of the two variables that yields an acceptable current account deficit (CAD) B of the balance of payments that sustainable capital flows can finance. For a given B, the current account worsens as the demand variable rises, while depreciation improves the CAD. So the curve slopes upwards. The CAD is lower than B above and higher below the EB schedule.

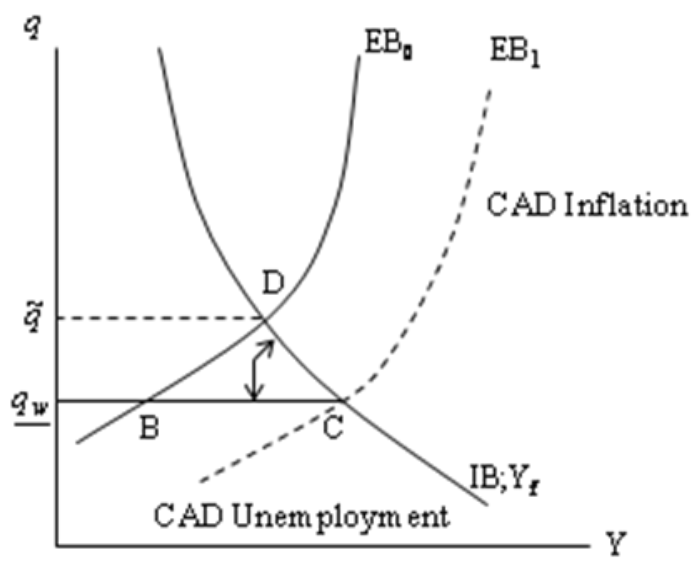

Figure 1: Internal and external balance with a real wage target

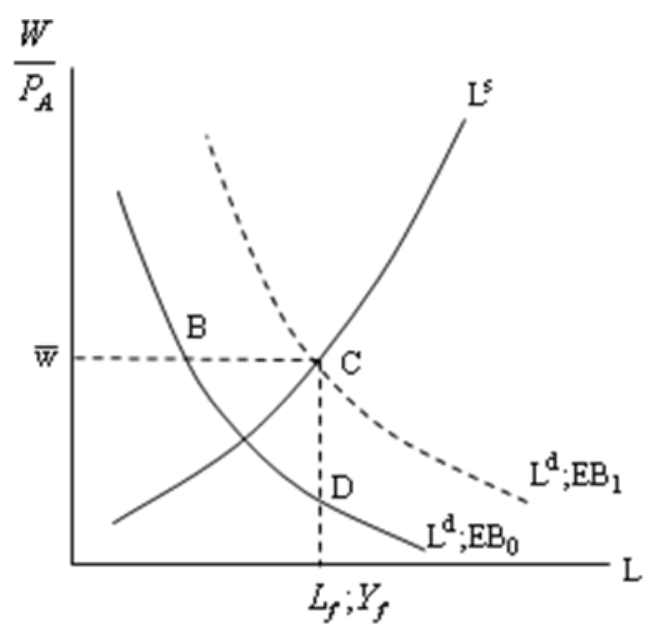

Figure 2: The labour market

Figure 1 shows internal and external balance in the space of $\mathrm{q}$ and $\mathrm{A}$ and Figure 2 the underlying labor market equilibrium. IB and EB are satisfied at the equilibrium real exchange rate, $\tilde{q}$. 
Proposition 3: There is a ceiling level of the real exchange rate, $q_{w}$, which satisfies the real wage floor $\bar{w}$.

Proof: The target real wage gives a wage floor which written in log levels is: $\bar{w}=w_{t}-p_{\mathrm{A}}$; wages cannot fall below this in the medium-term. The log real exchange rate $\mathrm{q}$ is equal to $\mathrm{p}_{\mathrm{A}^{-}} \mathrm{p}_{\mathrm{N}}$. The $\log$ prices of nontraded goods equal costs of production giving $\mathrm{p}_{\mathrm{N}}=\mathrm{w}-\mathrm{a}_{\mathrm{N}}^{8}$. Setting $\mathrm{w}$ at the value satisfying $\bar{w}$, gives the corresponding real exchange rate, $\mathrm{q}_{\mathrm{w}}=\mathrm{p}_{\mathrm{A}}-\mathrm{p}_{\mathrm{N}}$, that satisfies the wage target and the wage-price relations for the two sectors. Substituting for $w$ in the price setting equation, we get $p_{N}=p_{A}+\bar{w}-a_{N}$. Substituting $q_{w}=p_{A}-p_{N}$ gives $q_{w}=a_{N}-\bar{w}$ A more depreciated $\mathrm{q}>\mathrm{q}_{\mathrm{w}}$ would lower real wages below the floor, so $q_{w}$, is the ceiling level of the real exchange rate, which satisfies the real wage floor $\bar{w}$.

Since the value of $\mathrm{q}_{\mathrm{w}}$ is $\mathrm{a}_{\mathrm{N}}-\bar{w}$ the real exchange rate ceiling falls as the real wage floor rises. If $\bar{w}$ is itself rising and $\dot{\bar{w}}=\dot{a}_{A}, \dot{q}_{w}=\dot{a}_{N}-\dot{a}_{A}, \dot{q}_{w}$ can only rise if productivity growth in non-traded goods exceeds that in traded goods. If the ceiling rises, to that extent the real exchange rate can depreciate without creating inflation. In an EDE, and as the BS result requires, $\dot{a}_{A}<\dot{a}_{N}$ so $\dot{q}_{w}>0$, so the exchange rate ceiling rises. If $\dot{\bar{w}}=\dot{a}_{N}, \dot{q}_{w}=0$, and the ceiling cannot rise in this case.

Proposition 4: If $q>q_{w}$ then further rounds of inflation occur.

Proof: If the level of q equilibrating IB and EB is $\tilde{q}$, and it exceeds $\mathrm{q}_{w}, \mathrm{q}$ will tend to rise to reduce the CAD at any $q<\tilde{q}$ requiring a real depreciation. Capital outflows can induce such a depreciation of q. But if $q>q_{w}$ then $p_{A}$ is higher than that required by wage floor. Since the minimum wage is not attained, wages rise in an attempt to reach $\bar{w}$. But as costs rise, so does $p_{N}$, pushing $q$ back towards $q_{w}$. Any shock raising $\mathrm{q}$ to $\tilde{q}$ again will sustain the process and inflation will continue.

\footnotetext{
${ }^{8}$ Differentiating this equation gives (7), after substituting $\dot{w}=\dot{\bar{w}}+\pi_{A}=\dot{a}_{A}+\pi_{A}$.
} 
The horizontal line at $\mathrm{q}_{w}$ in Figure 1 shows the level of $\mathrm{q}$ satisfying the real wage floor. The level equilibrating IB and EB is $\tilde{q}$. If $\tilde{q}$ exceeds $\mathrm{q}_{w}$, there exists a triangular region DBC, with unemployment and a CAD. If $\tilde{q}$ exceeds $\mathrm{q}_{w}$, $\mathrm{q}$ will be in DBC and inflation will continue. The arrows show the direction of motion. Inflation is too high if $q>q_{w}$, and the CAD is too large if $\tilde{q}>q$. Nominal depreciation to improve the CAD will raise $p_{A}=\mathrm{s}+\mathrm{p}_{\mathrm{A}} *$ and spark another rise in $w$. For the system to settle down it must be that $q=q_{w}=\tilde{q}$.

For example a nominal depreciation in period one would immediately raise $\pi_{\mathrm{A}}$, and the sequence would play out as below:

$$
\pi_{A 1}=\dot{s}_{1} \quad, \quad \pi_{A 1}>\pi_{A 0}
$$

Where $0,1,2 \ldots$ are time subscripts assuming a lag in price setting in sector $\mathrm{N}$ and $\dot{a}_{A}=\dot{a}_{N}=0, \pi_{N 1}=\pi_{A 0}$, so

$$
\begin{aligned}
& \dot{q}_{1}=\pi_{A 1}-\pi_{A 0}>0 \\
& q_{1}>q_{0}=q_{w}
\end{aligned}
$$

But in the next period $\pi_{\mathrm{N}}$ rises since $\pi_{\mathrm{N} 2}=\pi_{\mathrm{A} 1}$, bringing $\mathrm{q}_{2}$ back towards $\mathrm{q}_{\mathrm{w}}$. Aggregate inflation is positive until $\mathrm{q}=\mathrm{q}_{\mathrm{w}}$. If lags are larger or further shocks to $\mathrm{S}$ occur, the process can take longer and inflation can continue. If $\dot{a}_{A}<\dot{a}_{N}, \mathrm{q}_{\mathrm{w}}$ itself rises, and the rise in $\pi_{\mathrm{N}}$, and in inflation is somewhat reduced.

$$
\begin{aligned}
& \pi_{N 2}=\pi_{A 1}+\dot{a}_{A}-\dot{a}_{N}=\pi_{A 1}-\dot{q}_{w} \\
& \text { So, } \pi_{N 2}<\pi_{A 1} \text { to the extent } \dot{q}_{w}>0 .
\end{aligned}
$$

So in an $\operatorname{EDE} q$ can rise without causing inflation to the extent $q_{w}$ increases or $\dot{a}_{N}>\dot{a}_{A}$

Figure 2 shows the corresponding labor market equilibrium. The labor demand curve $\mathrm{L}^{\mathrm{d}}$, corresponding to $\mathrm{EB}_{0}$, slopes downwards. Since it corresponds to $\mathrm{EB}_{0}$, it has absorption adjusted, given the level of $\mathrm{q}$, to achieve a given current account. As q and $p_{A}$ rise, the real product wage in traded goods falls and labour demand rises. Labour supply rises with real wages, but wages cannot rise above the floor until full employment is reached; they cannot fall below the floor because of the wage target. 
This real wage rigidity prevents the effective use of price switching, and can keep the economy in the region of unemployment and a current account deficit.

Even if $q_{w}$ rises, the triangle can still exist, or other shocks can raise $\tilde{q}$, keeping the economy within the inflationary triangle. For example a fall in global demand shifts both the IB and EB schedules of in Figure 1 upwards, raising $\tilde{q}$.

Since a rise in absorption, such as a rise in government expenditure, makes the CAD worse, the economy may be stuck around B in Figure 1, with large unemployment. Output is demand determined below the IB schedule and limited by available labor supply above it. But even with unemployment there is inflation. So the AS derived for such an economy would be flat, because of unemployment, but subject to upward shifts because of the wage price spiral (Goyal, 2010).

A key component of the type of inflation discussed in sections 3 and 4 is the effect of food price inflation and nominal depreciation on wages. High Indian inflation since 2007 was accompanied by high food inflation and episodes of depreciation. To the extent these affected wages it would support the existence of a real wage and exchange rate target, and suggest the framework above may help explain inflation in India.

\section{Wages and inflation}

Indian real wages for rural unskilled male labourers were constant over April 2002 to August 2007. But after that growth was positive, with nominal wage growth exceeding that in the relevant CPI index (RBI 2012 pp. 42). This could imply a real wage target that was now growing at or above labour productivity. The year 2007 saw a sharp rise in food prices due to international shocks, aggravated by the steep depreciation following the global financial crisis in 2008. The rains failed in 2009, leading to another spike in food inflation. The first phase of MGNREGS, a scheme guaranteeing 100 days of employment to each able bodied worker, was implemented on January 2, 2006, to cover 200 districts. It was extended to another 130 districts in 2007-2008, and to the whole country from April 1, 2008. Although the primary goal was insurance, labour employed was to be used to create productive assets, such as for 
water harvesting, which could raise agricultural productivity. It is often claimed MGNREGS raised rural unskilled wage growth above rural productivity growth.

State level wage data, made available only recently, make it possible to try and disentangle effect of these various factors on rural wages. The State level daily wages panel for manual agricultural labour, over the period January 2008 to December 2010, was obtained from the Economic Times, July 7, 2011. The original source, the Labour Bureau, Shimla, does not make the data freely available. Data for other macroeconomic variables sources were sourced from the RBI database. All the variables were deseasonalized, transformed into log values, and then year on year log differences were taken to get growth rates. Annualized growth rates were used-that is January 2009 over January 2008 and so on. All the variables were tested for unit root but were found to be stationary.

This period forms a perfect natural experiment. That, and the State panel, compensates partly for the short length of the series. It was a period of sharp rise in food prices and exchange rates due to external and therefore exogenous shocks, and was also the period of nationwide implementation of MGNREGS.

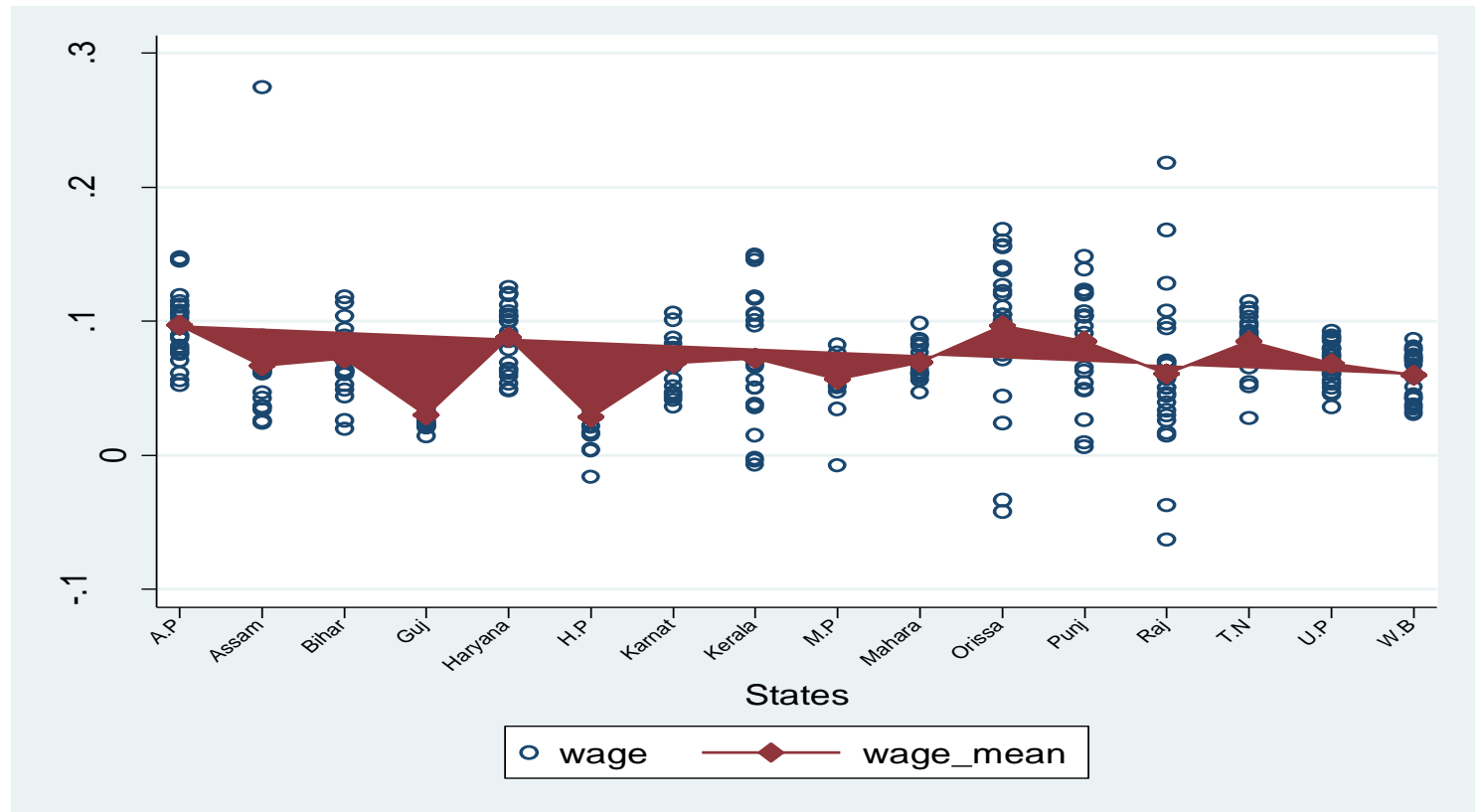

Figure 3: Heterogeneity across States in wages 


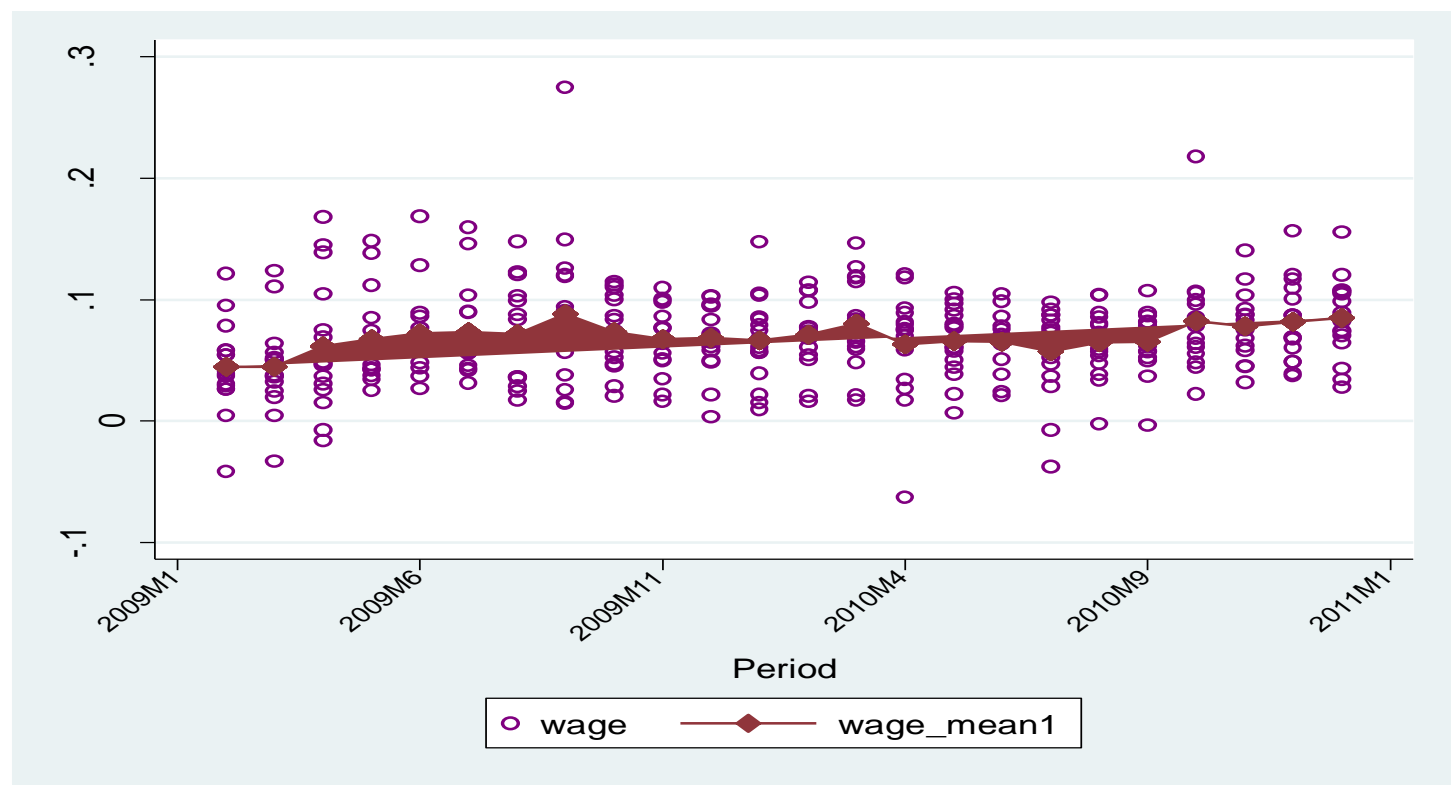

Figure 4: Heterogeneity across months in States wages

\begin{tabular}{|c|c|c|c|c|}
\hline \multicolumn{5}{|c|}{ Table 1: Summary statistics for wages across States } \\
\hline States & Mean & $\begin{array}{l}\text { Std. } \\
\text { Dev. }\end{array}$ & Min & Max \\
\hline Andhra Pradesh & 0.10 & 0.03 & 0.05 & 0.15 \\
\hline Assam & 0.07 & 0.05 & 0.02 & 0.27 \\
\hline Bihar & 0.07 & 0.02 & 0.02 & 0.12 \\
\hline Gujarat & 0.03 & 0.01 & 0.01 & 0.04 \\
\hline Haryana & 0.09 & 0.02 & 0.05 & 0.13 \\
\hline Himachal Pradesh & 0.03 & 0.02 & -0.02 & 0.06 \\
\hline Karnataka & 0.07 & 0.02 & 0.04 & 0.11 \\
\hline Kerala & 0.07 & 0.05 & -0.01 & 0.15 \\
\hline Madhya Pradesh & 0.06 & 0.02 & -0.01 & 0.08 \\
\hline Maharashtra & 0.07 & 0.01 & 0.05 & 0.10 \\
\hline Orissa & 0.10 & 0.05 & -0.04 & 0.17 \\
\hline Punjab & 0.09 & 0.04 & 0.01 & 0.15 \\
\hline Rajasthan & 0.06 & 0.06 & -0.06 & 0.22 \\
\hline Tamil Nadu & 0.09 & 0.02 & 0.03 & 0.11 \\
\hline Uttar Pradesh & 0.07 & 0.02 & 0.04 & 0.09 \\
\hline West Bengal & 0.06 & 0.02 & 0.03 & 0.09 \\
\hline \multicolumn{5}{|c|}{ Summary Statistics for Macro Variables } \\
\hline WPI food inflation & 0.06 & 0.02 & 0.03 & 0.09 \\
\hline CPI inflation & 0.05 & 0.01 & 0.03 & 0.07 \\
\hline Exchange Rate depreciation & 0.01 & 0.05 & -0.05 & 0.11 \\
\hline IIP Growth & 0.04 & 0.02 & 0.00 & 0.07 \\
\hline
\end{tabular}

Figures 3 and 4 and Table 1 show a large dispersion of wages across States and over time- - State specific factors were also at play. States with high wage inflation were: Andhra Pradesh, Haryana, Orissa, Punjab and Tamil Nadu. The States with low wage inflation were Gujarat, Himachal Pradesh, Rajasthan, Madhya Pradesh and West Bengal. 
Rajasthan, Chhatisgarh, Andhra Pradesh and Madhya Pradesh were the States that on average performed better than other states over 2008-10 in terms of universal coverage of the rural population under the MGNREGS (Garg, 2011). But the States with the highest wage levels in this period were Haryana, Punjab and Kerala in that order. The States that implemented MGNREGS effectively had neither the highest wage levels nor, with the exception of Andhra Pradesh, had the highest rates of wage growth. The average daily MGNREGS wage paid in 2009-10 was Rs 90.2 but was Rs 150.9 in Haryana (Garg, 2011). In 2009 the notified daily MGNREGS wage was raised to Rs 100 in most States, but was indexed to the Consumer Price Index for Agricultural Labour only on April 1, 2012 ${ }^{9}$. During our data period there was no indexation.

Table 1 also gives the summary statistics for the macroeconomic variable used in the regressions: Change in the nominal INR/USD exchange rate, output growth proxied by the IIP index, inflation based on CPI and WPI food indices. Food has a weight of above 40 percent in the CPI index.

\begin{tabular}{llc}
\hline \multicolumn{3}{c}{ Table 2: Determinants of wage inflation in the States } \\
\hline Variables & \multicolumn{1}{c}{2} & \multicolumn{1}{c}{3} \\
\hline Lag WPI (food) inflation & $0.531(2.57)$ & $0.240(2.95)$ \\
Lag Exchange rate depreciation & $0.170(3.41)$ & $1.04(15.93)$ \\
Lag CPI inflation & $0.649(2.49)$ & \\
R square & 0.445 & 0.512 \\
\hline Note: Correlation between errors and regressors were found to be 0. Pesaran's test of cross \\
sectional independence $=1.676$, Prob= $0.0936 ;$ t statistics are given in brackets. \\
\hline
\end{tabular}

Three sets of regressions are reported in Tables 2 and 3. Column 2, Table 2 reports the results of regressing wage inflation for all the States on the set of macro variablesindustrial growth, inflation and depreciation. Column 3, Table 2 reports the results of regressing average wage inflation across all States on the set of macro variables.

\footnotetext{
${ }^{9}$ Other sources http://www.thehindu.com/news/national/article3247684.ece also http://nrega.nic.in/nerega_statewise.pdf
} 


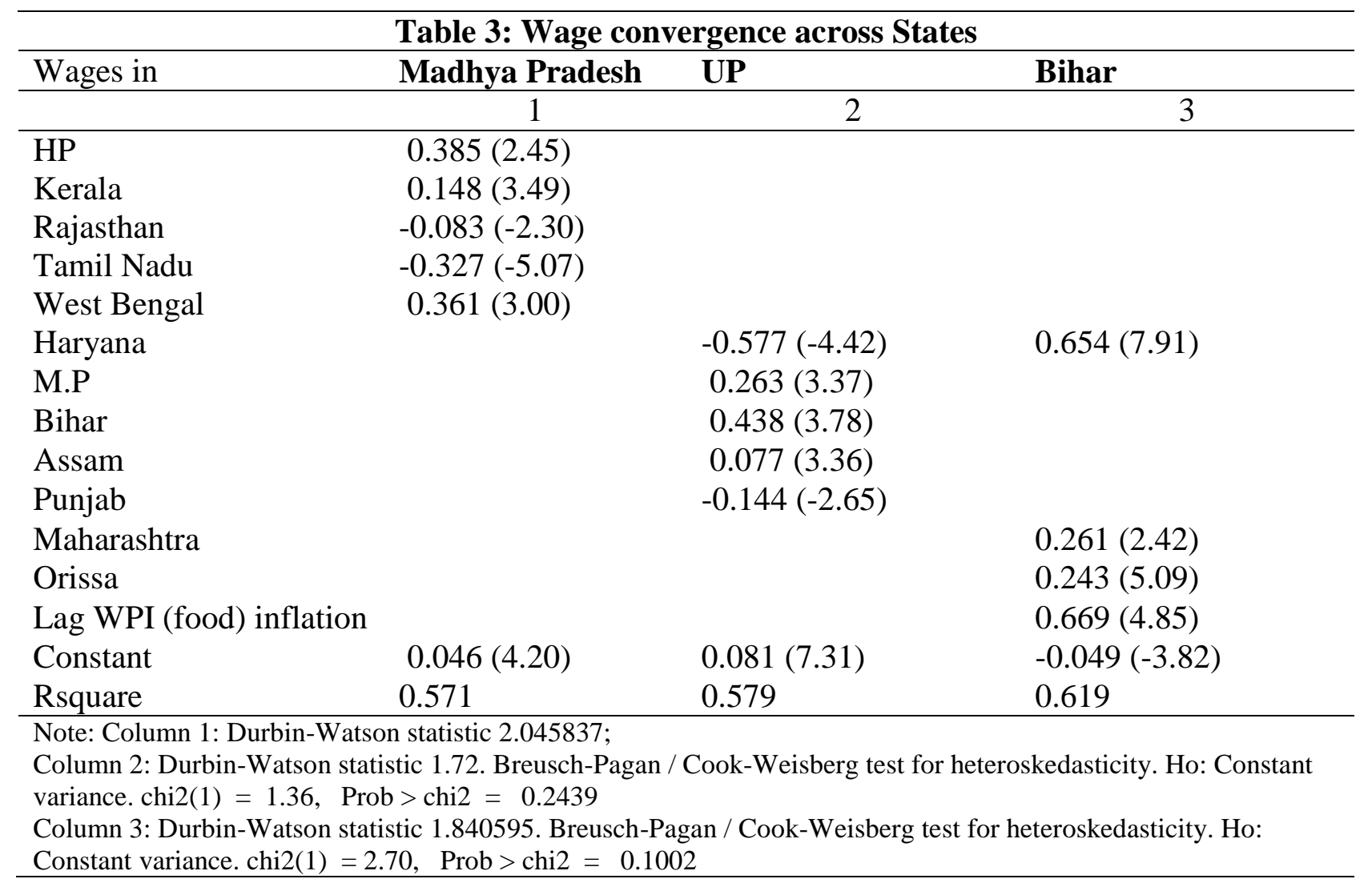

Wherever heteroskedasticity was found, the Prais-Winsten regression was used for robust errors. Pesaran CD (cross-sectional dependence) test was used to test whether the residuals are correlated across entities. Cross-sectional dependence can lead to bias in tests results (also called contemporaneous correlation), but the null hypothesis that residuals are not correlated was accepted.

While the output growth variable was not significant, both food inflation and exchange rate depreciation had highly significant positive effect on average and individual State wage inflation. Thus it was not demand factors as much as cost of living factors that pushed up wages.

The third set regressed all low wage inflation States on macro variables and wage inflation in all other States, dropping insignificant variables. The idea was to test if wage growth in one State affected wage growth in the other. If MGNREGS was 
pushing up wages, such an effect should be observed. Table 3 reports the results for Madhya Pradesh, UP and Bihar ${ }^{10}$.

The States do affect each other, but it is not necessary that a high wage State pulls up wages in other States. States with high wage growth sometimes enter with a negative sign, and none of the States with the most effective implementation of MGNREGS pushed up wage growth in any other. Macro variables become insignificant (except that lagged WPI food inflation still pushes up wage growth in Bihar) when States are included in the set of regressors perhaps because of multicollinearity due to the large number of variables.

But the first two sets of regressions show cost-side macroeconomic variables clearly pulling up wages in the States. The absence of a clear impact of one State's wages on the other, and that wage growth was low in States that implemented MGNREGS effectively, suggest cost push macroeconomic variables were more causative than the MGNREGS, that was widely regarded as pulling up wages. Aggregate demand variables also did not push up wages.

\section{Policy}

The analysis implies the nominal exchange rate must be managed to prevent excess capital flow driven volatility. Exchange rate policy also has other uses. A nominal appreciation in response to a temporary rise in international traded goods prices can prevent such a rise from starting a wage price spiral that would otherwise sustain inflation as in Figure $1^{11}$.

Figure 5 graphs IB and EB curves which have a similar interpretation as in Figure 1, but using the nominal exchange rate $\mathrm{S}$ as the switching variable and government expenditure $\mathrm{G}$ as the absorption or demand variable.

\footnotetext{
${ }^{10}$ Other regressions not reported here are available on request.

${ }^{11}$ This section draws on material from Goyal (2010).
} 


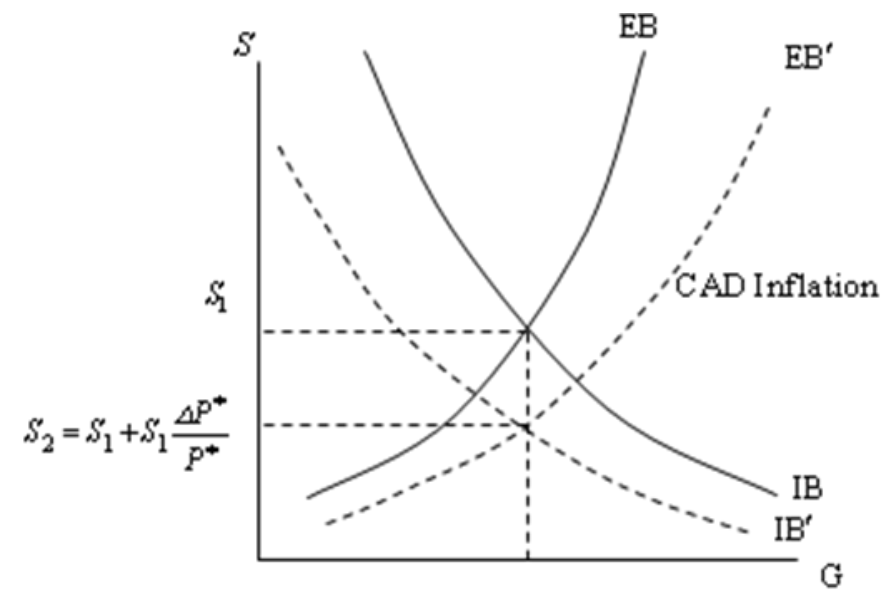

Figure 5: Aborting a foreign price shock

In Figure 5, the amount by which the nominal exchange rate has to appreciate to counter the change in $\mathrm{P}^{*}$, shows how much both curves shift downwards proportionately after a rise in $\mathrm{P}^{*}$. This amount is $\mathrm{S} \Delta \mathrm{P}^{*} / \mathrm{P}^{*}$. The old equilibrium with the rise in $\mathrm{P}^{*}$ and unchanged $\mathrm{S}$ will now be a position of excess demand and an acceptable CAD or a surplus. Domestic prices will tend to rise as a result. If inelastic intermediates dominate the import basket, depreciation will not improve the current account. The IB will shift further down, since goods market equilibrium will require $S$ to appreciate, while the $\mathrm{EB}$ will shift out since the required rise in net exports may require a larger depreciation. The original position will now show inflation and a CAD. A simple nominal appreciation proportional to the change in $\mathrm{P}^{*}$ can abort the process, taking the economy to the new equilibrium where IB' and EB' intersect, since the appreciation in $\mathrm{S}$ compensates for the rise in $\mathrm{P}^{*}$. Such an aborting is especially useful if the rise in international prices can set off a domestic wage-price spiral, such as occurs if the economy is caught in the region DBC of Figure 1.

An aggressive monetary tightening can reduce demand, shifting the IB curve leftwards and closing the inflationary triangle. But there is a large output sacrifice as the economy reaches B, much below full employment output. Inflows can appreciate the exchange rate thus satisfying the wage target and finance the accompanying rise in imports, taking the economy to $\mathrm{C}$. But widening of the current account deficit (CAD) is risky although it allows investment to exceed domestic savings. A reversal of inflows due to an external shock can cause a sharp depreciation. Rising productivity increases the level of inflows that can be safely absorbed at a reasonable CAD. 
Short-run policies work only for a temporary shock. A permanent shock requires a productivity response. The fundamental reason for chronic supply side driven inflation is that target real wages exceed labour productivity, so the solution is to raise worker productivity. A rise in productivity of nontraded goods $\left(\dot{a}_{N}>0\right)$ can shift up the target real exchange rate, so the wage target can be satisfied at a more depreciated exchange rate. It increases the real wage and exchange rate compatible with low inflation, thus breaking the propagation mechanism.

Higher agricultural productivity $\left(\dot{a}_{A}>0\right)$ is especially important because food prices are an inflation trigger. The nominal exchange rate can appreciate with a rise in agricultural productivity, bringing the real exchange rate closer to the target real exchange rate and closing the inflationary gap between them.

\section{Conclusion}

Trade arbitrage should imply goods cost the same across two countries in the same currency, thus fixing the real exchange rate. But there are large deviations from this purchasing power parity exchange rate. This is the first puzzle. One resolution brings in nontraded goods. BS showed then that the price level is higher in AEs. But a second puzzle is that inflation is consistently higher in EDEs. We provide a new proof of the standard BS result in a simple framework and then extend it by dropping the assumption that the price level is fixed in the EDE. Our extension reconciles the BS result with higher inflation in EDEs and persistent deviations in the real exchange rate.

Shocks such as nominal depreciation and rise in nominal wages, explain the higher EDE inflation. We also show how a real wage target in terms of food prices can sustain inflation as nominal wages rise in response to a nominal depreciation. The result is particularly relevant as large capital flows drive exchange rates and interact with different types of wage rigidities in EDEs today. Inflation is normally associated with excess money creation that also drives nominal depreciation. The paper shows external shocks can cause inflation independent of changes in money supply. 
Empirical evidence that food inflation and nominal depreciation affected wages during India's high inflation episode after 2007, supports the framework developed. Neither aggregate demand variables nor MGNREGS had a significant effect on wage inflation. The dataset had the advantage of external shocks cutting through possible endogeneity but the results need to be confirmed with a larger data set which will make it possible to use a larger set of instruments and other control variables. Independent estimates of productivity growth in the two sectors will also help.

Implications for policy include managing the nominal exchange rate to prevent excess capital flow driven volatility. Exchange rate policy can also be used to abort external price shocks that can otherwise set off a wage-price spiral. In the longer-term, of course, improvements in productivity are required that remove the shortfalls in actual from target wages and the gaps between target and equilibrium real exchange rates that otherwise tend to sustain inflation.

\section{References}

Balassa, B. (1964). 'The purchasing power parity doctrine: A reappraisal'. Journal of Political Economy. 72, December, pp. 584-596.

Bhagwati, J. N. (1984). 'Why are services cheaper in the poor countries?' Economic Journal. 94 (June), pp. 279-286.

Froot, K. A. and K. Rogoff. (1995). 'Perspectives on PPP and long-run real exchange rates'. Handbook of International Economics, in: G. M. Grossman \& K. Rogoff (ed.), Handbook of International Economics, edition 1, volume 3, chapter 32, pp. 1647-1688 Elsevier.

Garg, S. (2011). 'Mahatma Gandhi National Rural Employment Guarantee Act: Coverage, requirement and provisions'. Mphil thesis, IGIDR. December.

Goyal, A. (2010). 'Inflationary pressures in South Asia'. Asia-Pacific Development Journal Vol. 17(2), pp. 1-42. December.

Goyal, A. (2012). 'Propagation mechanisms in inflation: Governance as key'. Chapter 3 in S. Mahendra Dev (ed.), India Development Report. pp. 32-46. New Delhi: IGIDR and Oxford University Press.

Lewis, W.A. (1954). 'Economic development with unlimited supplies of labour'. The Manchester School, 22(2), pp. 139-191.

Rogoff, K. (1996). 'The purchasing power parity puzzle'. Journal of Economic Literature. 34 (June), pp. 647-688. 
RBI (Reserve Bank of India). 2012. 'Macroeconomic and monetary developments'. Second Quarter Review, October 29.

Samuelson, P. A. (1964). 'Theoretical notes on trade problems'. Review of Economics and Statistics. 46 (May), pp. 145-154.

Summers, R. and A. Heston. (1991). 'The Penn world table (mark 5): An expanded set of international comparisons, 1950-1988'. Quarterly Journal of Economics. 106 (May), pp. 327-368. 